\title{
Analysis of Underground Mining Accidents at AngloGold Ashanti Limited, Obuasi Mine*
}

\author{
N. Amegbey, S. Ndur, and R. K. Adjei
}

Amegbey, N., Ndur, S. and Adjei, R. K. (2008). “Analysis of Underground Mining Accidents at AngloGold

Ashanti Limited, Obuasi Mine”, Ghana Mining Journal, pp. 25 - 29.

\begin{abstract}
Analysis of incidents at AngloGold Ashanti's (AGA's) largest mine in Ghana was carried out to study accidents and injuries from underground mining activities, and to assess the effects of accidents on AGA's production. Ground fall, machinery, electrocution and slip fall were the main causes of mine accidents. Results agree fairly well with those of other mines and production declined with increased lost-time injury frequency rate (LTIFR).
\end{abstract}

\section{Introduction}

Mining activities are generally associated with poor working conditions and accidents that result in injuries, labour inefficiency and low production. The adverse effect of these injuries resulting from accidents, in particular, has become a matter of concern in both industrialized and developing countries. As a result comprehensive safety regulations are established throughout the world to curb this menace. Mining accidents cannot be eliminated entirely; the strategy adopted worldwide is to control their frequency and severity in order to save human life and boost production, since 98\% of mining accidents are of a preventable kind (Anon, 1995).

Mine accidents statistics are available in most developed countries (Anon, 1994); however, there is minimal public information on mine accidents in developing countries. AngloGold Ashanti (AGA), Obuasi mine is one of the largest gold mines in the world. It produces over a million tonnes of ore per year. AngloGold Ashanti employs both surface and underground mining methods in its operations at Obuasi. Underground mining operations contribute at least $90 \%$ of gold produced at AGA. Accident rate at AGA Obuasi Mine is of major concern to management.

Records from the mine show that underground mining activities have higher accident rates than the surface operations (78\% for underground and $22 \%$ for surface operations). In this study, the authors present analyses of underground mine accidents at AGA, Obuasi mine located in Ghana.

\subsection{Location of the Mine}

The AngloGold Ashanti Limited (AGA) is located at Obuasi, the capital of the Obuasi Municipal Assembly of Ashanti Region, $60 \mathrm{~km}$ southeast of
Kumasi, the regional capital and 175 km northwest of Accra, the capital of Ghana. The area covered by the Obuasi mine is located in the tropical rainforest zone and experiences a tropical climate. This climate is characterized by a rainy season from late April to early August with the peak occurring from May to June and minor intermittent rainfall from December to February. The highest rainfall is recorded in June with an average of 3.8 $\mathrm{cm}$. The annual rainfall is about $4.5 \mathrm{~cm}$. The average minimum and maximum temperatures are 25 ${ }^{\circ} \mathrm{C}$ and $35^{\circ} \mathrm{C}$ respectively.

\subsection{Mining and Ore Processing Practices at AGA}

At AGA, Obuasi, both underground and surface mining operations are employed to exploit the ore. The deposit is mined by a system of vertical shafts, mostly sunk in the footwall of the ore body. Main levels are then put at $30.5 \mathrm{~m}$ vertical intervals. The mine is currently serviced by seven vertical shafts, two sub-vertical shafts and one ramp (Sansu down ramp). The mining methods employed underground may be classified mainly as sublevel caving and open stoping. The sublevel caving method is practiced in the wider dyke, schist and composite ore bodies. This enables the low grade ore to be mined in bulk by the use of mechanised equipment. Sublevel caving methods being applied at AGA are the longitudinal and transverse extraction of the mining block at the West Waley Shaft (Blocks 5 and 6). Open Stoping method is employed mainly at the Adansi North, Central and the South Mine since the ore bodies in these areas are rich, massive and wide.

Surface mining operation has declined due to depleted ore. At the moment, cutback is done at the Sibi Pit with only one excavator (PC 1100) and

* Manuscript received June 14, 2008

Revised version accepted October 12, 2008 
two trucks (HD 325). The mainly oxide ore is hauled by trucks to the Oxide Treatment Plant (OTP).

There are three main treatment plants at AGA. These are the Tailings Treatment Plant (TTP), Oxide Treatment Plant and Sulphide Treatment Plant (STP). The TTP processes mined old tailings, oxide ores are processed at the OTP while sulfide ores are processed at STP, which employs the Biological oxidation (BIOX) pretreatment method.

\section{Data Collection}

Accidents that occurred at AGA from 2000 to 2005 were collected from the departmental files and personal accident records at the Safety and Health Department (SHD). All incidents that occur underground and on the surface are captured by filling an incident report form (Mines Form 7) and forwarded to the SHD for investigation and remedial action. The incident report form served as the main source of data for this paper. Discussions with Safety Officers, some management personnel and other members of the workforce provided additional information.

\section{Results}

\subsection{Incident Statistics}

The total underground incidents reported during the study period as captured in the incident report forms is 1502 comprising 120 near-misses, 810 minor injuries, 313 disabling injuries, 240 serious injuries and 19 fatalities (Fig.1).

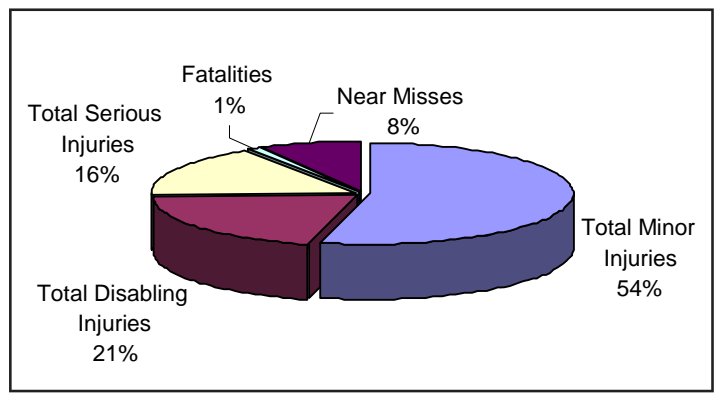

Fig. 1 Underground Incident Statistics from 2000 to 2005

\subsection{Accident and Injury Statistics}

Fig. 2 gives accident statistics from 2000 to 2005 for total manshifts worked, manshifts lost due to accident, total lost-time injuries (LTI), number of fatalities (FA), LTI frequency rate (LTIFR), and severity rate (SR). Lost-time injury frequency rate and Severity Rates were calculated for each year using the relationships:

LTIFR $=\frac{\text { Total Lost }- \text { time Injuries } \times 1000000}{\text { Total Man }- \text { Hours Worked }}$

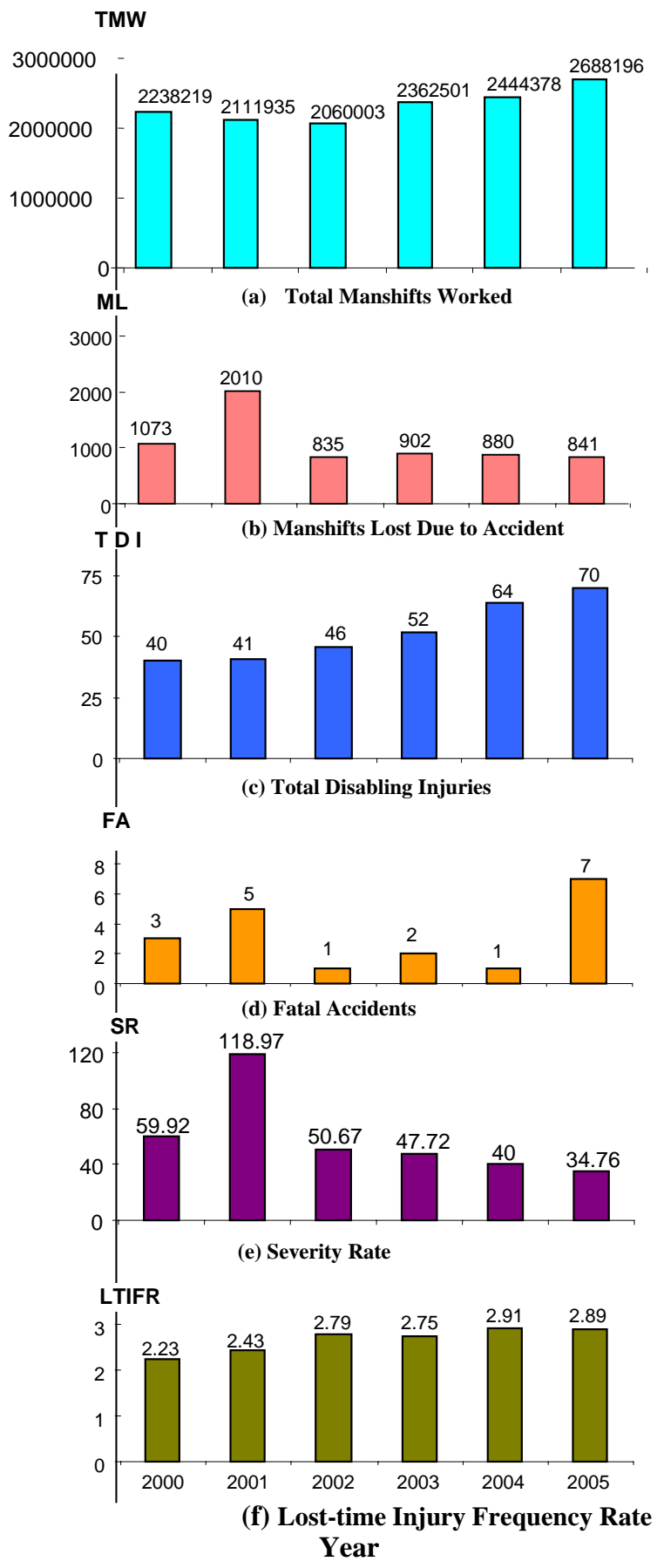

Fig. 2 Accident Statistics

and

SR $=\frac{\text { Total Manshifts Lost } x 1000000}{\text { Total Man }- \text { Hours Worked }}$

The data was further analysed for the following:

- Causes of Underground Fatal Accidents (Fig. 3)

- Underground Fatal Accidents by Occupation (Fig. 4)

- Underground Accident by Day of Occurrence (Fig. 5) 
- Underground Accident by Shift of Occurrence (Fig.6)

- Injury by Body Parts from Underground Accidents (Fig.7)

- Injury by Unsafe Acts/Condition from Underground Accidents (Fig.8)

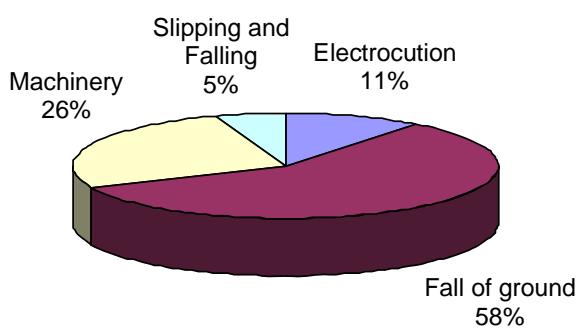

Fig. 3 Causes of Underground Fatal Accidents

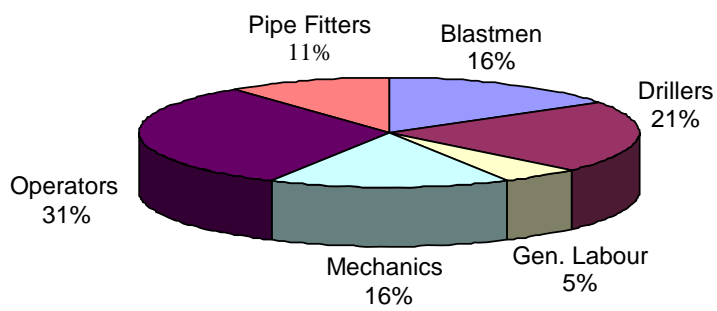

Fig. 4 Underground Fatal Accidents by Occupation

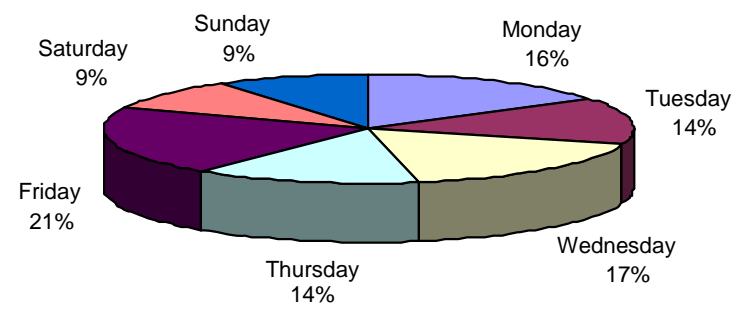

Fig. 5 Underground Accident by Day of Occurrence

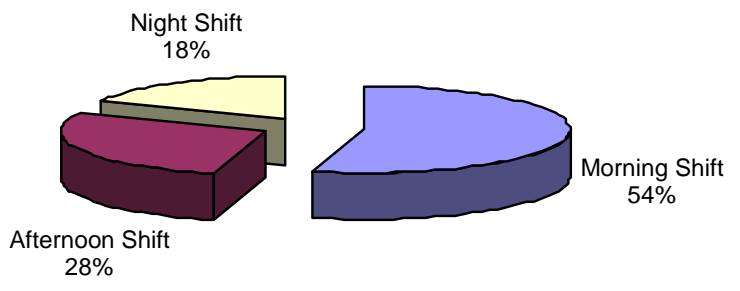

Fig. 6 Underground Accident by Shift of Occurrence

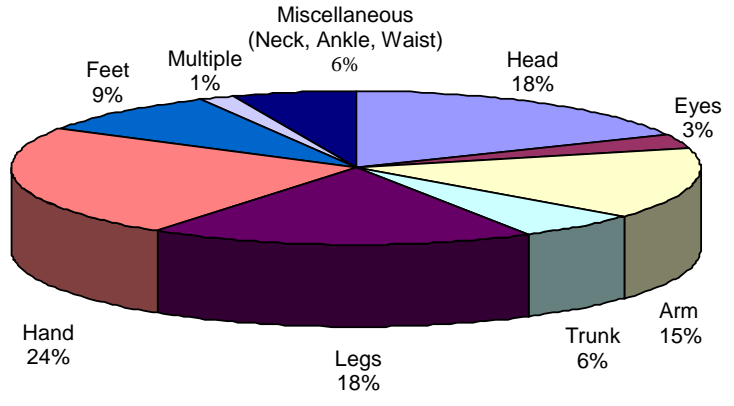

Fig. 7 Injury by Body Parts from Underground Accidents

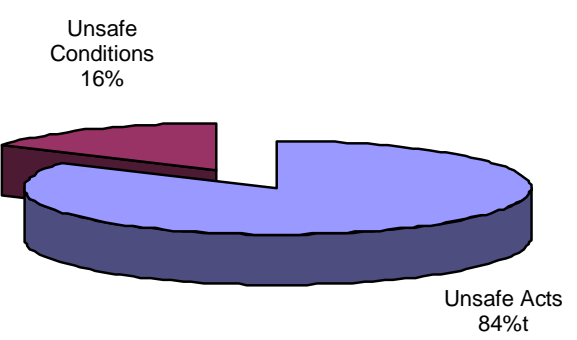

Fig. 8 Injury by Unsafe Acts/Conditions from Underground Accidents

\subsection{Effect of Accident on Total Gold Produc-} tion

In order to study the effect of accidents on production at AGA, Obuasi, Total Disabling Injuries was plotted against gold production over the period of study. The result is shown in Fig. 9

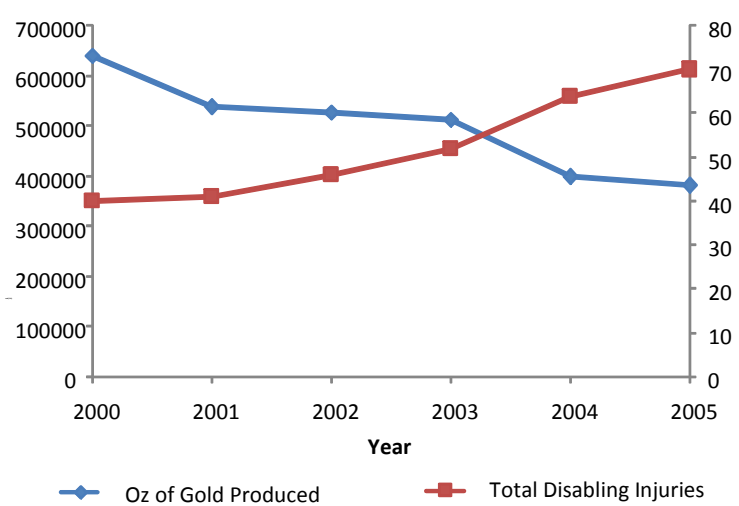

Fig. 9 Gold Production and Total Disabling Injuries

\section{Discussion}

\subsection{Total Underground Incidents}

Details of the total underground incidents at AGA, Obuasi, within the study period (Fig.1) show a very low proportion (8\%) of near-misses. Accord- 
ing to Bird and Loftus (1976) the ratio Serious Injury/Fatality : Property Damage : Minor Injuries : Near-misses is $1: 10: 30: 600$, commonly referred to as the Frank Bird's Triangle. This means that for every 1 fatality, there should have occurred 600 near-misses (about 94\% of incidences are near-misses). This is not the case at AGA, Obuasi, where rather for every near-miss, 2 serious /fatal accidents occurred. Admittedly, it is possible that most near-misses go unreported. The culture of having all near-misses reported cannot be overemphasized as it helps in the management of hazards and accident reduction.

\subsection{Underground Accidents at AGA}

From Fig.2 (d) and (e) it can be inferred that most accidents that occurred in 2001 must have led to serious injuries, because the severity rate (SR) is high, and so also the fatalities. In 2005 there was an increase in total manshifts worked (TMW) and the total disabling injuries (TDI) [Fig.2 (a) and (c)]. The fatalities (FA) and the lost-time injury frequency rate (LTIFR) recorded the highest values, as seen in Fig.2 [(d) and (f)]. However, the manshift lost (ML) and SR were low [Fig.2 (b) and (e)]. Sometime in 2004 into 2005, management of the mine permitted underground workers one extra hour overtime work as a motivational package. Manshifts lost due to accidents decreased as more people reported for work and did not report to the hospital for just any minor injury. Consequently, the manshifts worked increased, and this might explain the reduction in SR. However, fatalities peaked to 7 during the period. From 2002 to 2005, TDI gradually increased from 46 to 70 yet ML was consistently low within the same period. This is because the accidents that occurred within the period did not lead to serious injuries. Indeed SR decreased from $50.67 \%$ to $34.76 \%$ within the same period. Lost-time injury frequency rate, however, increased slightly and within an acceptable range. According to International Safety Rating, arising out of audits by the National Occupational Safety Association (NOSA), average severity rate should not be more than 50 (Rimington, 1993). The severity rate for 2000 to 2002 at AGA, Obuasi were found to be higher than 50 .

\subsection{Fatalities}

From Figs.3, it is realized that, fall of ground caused most of the fatal accidents underground followed by machinery, electrocution and slip fall. Personnel mostly involved in fatal accidents are operators of scooptrams and drill rigs followed by drillers (operators of jacklegs and stopers), blastmen, mechanics, pipe fitters and general labour (Fig.4). Operators, drillers and blastmen are usu- ally found in stopes and development headings where actual mining operation takes place. This may account for the high rate of fatality within this group of workers. The fatal accidents that occurred as a result of ground fall recorded $58 \%$. In a NOSA circular (Anon, 1996), it is indicated that $55 \%$ of underground accidents that occured in the east region mines of South Africa, were due to ground fall. AGA, Obuasi results compare favourably with South African mine records.

\subsection{Underground Accident by Day of Occur- rence}

Analysis of underground accidents by day of occurrence showed that most of the accidents on the mine occur on Fridays (Fig. 5). The probable reason is that most workers ask permission to attend social functions such as funerals, weddings, parties, family gatherings, etc. during the weekends. As a result workers hurry to achieve their targets or assignments allotted to them by their supervisors so that they can leave earlier or avoid being delayed at the end of the shift. In the process more accidents occur.

\subsection{Underground Accident by Shift of Occur- rence}

From Fig.6, most of the accidents on the mine occur during the morning shift followed by the back shifts (afternoon and night). Generally, Senior Mine Officials such as Mine Managers, Underground Managers and Mine Captains visit underground workings during the morning shift. Accordingly, frontline supervisors (Shift Bosses) exert a lot of pressure on their subordinates in an attempt to put their house or workings in order (ensuring good housekeeping). This often leads to the higher accident or injury rate.

\subsection{Injury by Body Parts from Underground Accidents}

Injury classification according to body part shows that the hand is most liable to injury with $24 \%$ as compared to other parts of the body (Fig. 7). This is to be expected because it is the part of the human body that is most active in the various operations. Health and Safety Analysis Center (HSAC) data of the United States of America for 1981 indicates that there were 37017 accidents in the mining industry of which approximately $25 \%$ or 9,254 accidents resulted in hand injuries (Peay, 1983). Hand injury rate in Ghana agrees with this finding.

\subsection{Injury by Unsafe Act and Unsafe Condition from Underground Accidents}

In Fig. 8, it is observed that $84 \%$ of the causes of accidents are by unsafe acts or practices, while 
$16 \%$ is by unsafe conditions. This confirms the fact that unsafe practices are much harder to detect than unsafe condition type hazards and will often result in a larger percentage of accidents. Developing a "safety culture" best prevents unsafe acts (Anon, 1995). An important characteristic of unsafe condition types of hazards is that once the fundamental cause of their existence is found and acted upon, they do not usually reoccur for an extended period of time.

\subsection{Effect of Accident on Total Gold Production}

Rampant accidents and injuries seem to have effect on gold production as shown in Fig.9. A comparison of total disabling injuries to gold production shows that ounces of gold produced decrease as the disabling injuries increase. This is to be expected because whenever an accident occurs, some legal requirements must be adhered to. As a result of these requirements, some production time is always lost hence productivity is decreased.

\section{Conclusion}

From the analysis done in this work, it can be concluded that:

- Total incident and accident statistics at AGA Obuasi did not agree with the famous Frank Birds triangle in which 94\% near misses result in 1 fatality. At AGA, Obuasi, 8\% near misses resulted in 2 fatalities during the study period. Five fatalities were recorded in 2001 and seven in 2005.

- Ground fall accounted for most of the underground fatalities at AGA.

- The hand was more susceptible to injuries than other body parts, a result which agrees with findings in South African underground mines.

- More accidents occur during morning shifts than back shifts.

- More accidents occur on Fridays than the other days in the week.

- Unsafe acts resulted in more accidents than unsafe conditions.

- Production declined with increasing disabling injuries.

\section{References}

Anon. (1994), Fatal and Lost Time Injuries in Western Australian Mines 1993. Depart ment of Minerals and Energy, Western Australia, pp. 4, 23, 42-43.

Anon. (1995). Standard for Recording and Meas uring Work Injury Experience. Mines De partment, Ghana (Unpublished), pp 45-48.

Anon. (1996), Fatal Accidents in South African Mines, NOSA Information Circular on
S.A Mining Activities/1996, Unpublished. $71 \mathrm{pp}$.

Bird, F. E., Jnr. and Loftus, R. G. (1976), Loss Control Management Manual, Unpub lished, 79 pp.

Peay, J. M. (1983), “Hand Injuries” Information Circular/1983. Proceedings, Bureau of Mines Technology Transfer Symposia, Au gust 9, 1983, 23 pp.

Rimington, J. D. (1993), "Successful Health and Safety Management”, HSE Books, Sudbury, 66 pp.

\section{Authors}

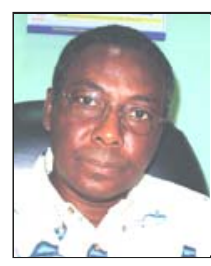

N. A. Amegbey obtained an MSc Degree in Mining Engineering from the Mining Institution of Petrosani, Romania in 1979. In 1987, he obtained a PhD ( Dr Ing) from the Technical University of Berlin, Germany. He worked as a Technical Mining Assistant at the former Tarkwa Goldfields Ltd. and currently is Professor and the Pro Vice Chancellor at the University of Mines and Technology, Tarkwa, Ghana. He lectures and provides consultancy services in Mine Environmental Engineering, Human Factor and Safety Issues. He is a Fellow of the Mine Ventilation Society of South Africa, a member of the German Society of Mining and Metallurgy and a member of the Society for Mining, Metallurgy and Exploration Inc of the United States of America. He serves on a number of international committees on environmental issues.

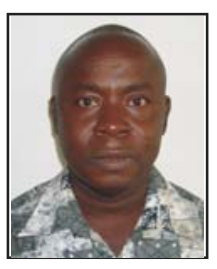

S. A. Ndur is a Senior Lecturer at the University of Mines and Technology, Tarkwa. He is currently the Head of the Mineral Engineering Department. He obtained his PhD (Geochemistry) from New Mexico Tech, USA and MSc (Petrochemical Engineering) from Moscow Institute of Oil and Gas, CIS. His research areas are Environmental Pollution and Control, Mine Waste Characterization and Management, and Water Quality Issues. He is a member of Society of Environmental Geochemistry and Health, American Society of Mine Reclamation and Geochemical Society.

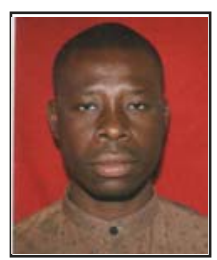

R. K. Adjei holds Diploma and M.Sc. degree in Mining Engineering from KNUST, Kumasi, Ghana. He worked at AngloGold Ashanti (Obuasi Mine) Ltd., first as a Technical Mining Assistant, then as a Shift Boss and Senior Underground Mine Planning Engineer. Mr. Kofi Adjei is currently working with the Inspectorate Division of the Minerals Commission as Inspector of Mines in charge of all the mining companies, quarrying, sand and stone winning and prospecting companies in the Northern sector of Ghana. 